\title{
A thermomechanical model for argillaceous rocks
}

\author{
Saeed Tourchi ${ }^{1}$, Antonio Gens ${ }^{2}$, Jean Vaunat ${ }^{2}$, Miguel Mánica ${ }^{3}$, Gianvito Scaringi ${ }^{1}$ \\ ${ }^{1}$ Institute of Hydrogeology, Engineering Geology and Applied Geophysics, Faculty of Science, Charles University, Albertov 6, 12800 \\ Prague, Czech Republic \\ ${ }^{2}$ Department of Civil and Environmental Engineering, Barcelona Tech. (UPC), Campus Nord UPC, 08034 Barcelona, Spain \\ ${ }^{3}$ Institute of Engineering, National Autonomous University of Mexico, Mexico City, Mexico
}

\section{Introduction}

This contribution is centred on the enhancement of an existing isothermal hydromechanical model for argillaceous rocks (Mánica et al., 2017) to provide predictive capability with respect to temperature changes. The model functions describing the yield locus, stiffness, and strength parameters are modified to consider the shrinking of the elastic domain and the degradation of stiffness and strength parameters with temperature. The developed thermomechanical constitutive model is then applied to the coupled thermo-hydro-mechanical (THM) analysis of an in-situ heating test (ALC1604) performed in the Meuse/Haute-Marne Underground Research Laboratory (Tourchi et al. 2020; Bumbieler et al. 2021). The relevance and importance of the temperature effect on the damaged zone around the tunnel are clearly demonstrated.

\section{Model Description}

The constitutive model describes two main deformation mechanisms: an instantaneous response related to stress and temperature changes and a time-dependent response occurring under constant stress. The time-dependent response is characterised by a modified form of Lemaitre's law. A generalised effective stress expression is adopted. The hypo-elastic volumetric strain increments are written as the sum of thermal and mechanical components. The dependence law for the thermal evolution of stiffness is expressed by (Tourchi 2020):

$$
E_{T}=E_{0}\left[1-\gamma \ln \left(T / T_{0}\right)\right],
$$

where $\mathrm{E}_{0}$ is Young's modulus at the initial temperature (T0.) and $\gamma$ is a temperature-independent constant. Two distinct sources of temperature-dependent variation of the yield locus that affect the form of the flow rule are considered (Tourchi 2020):

$$
\varphi=\varphi\left(\varepsilon_{e q}^{p}, \Delta T\right) \quad c=c\left(\varepsilon_{e q}^{p}, \Delta T\right),
$$

where $\varepsilon_{e q}^{p}$ is the plastic strain tensor. The thermal evolution of the internal friction angle is expressed by a linear relation (Tourchi 2020):

$$
\varphi_{T}=\varphi_{0}\left[1-\alpha \ln \left(T / T_{0}\right)\right],
$$

where $\varphi_{0}$ and $\varphi_{T}$ are the friction angles at the reference temperature (T0) and at a generic temperature (T), respectively. The coefficient $\alpha$ is a model parameter that controls the thermal evolution of the internal friction angle. The other parameter controlling the yield locus evolution is the cohesion strength which is assumed to vary with temperature in the same way as the friction angle. The friction angle varies in a piecewise manner as shown in Fig 1. A non-associated flow rule is adopted in the model. The plastic multiplier $\lambda$, which controls the plastic strain rate, is affected by the change in $\varphi$ and $\mathrm{c}$ (Tourchi 2020):

(4)

$$
\begin{aligned}
& d \lambda=\frac{1}{H}\left[\frac{\partial f}{\partial \sigma^{\prime}}: \sigma^{\prime}+\left(\frac{\partial f}{\partial \varphi} \frac{\partial \varphi}{\partial T}+\frac{\partial f}{\partial c} \frac{\partial c}{\partial T}\right) d T\right] \geq 0 \\
& H=-\frac{\partial f}{\partial \varphi} \frac{\partial g}{\partial \sigma^{\prime}} \frac{\partial \varphi}{\partial \varepsilon_{v}^{p}}+\frac{\partial f}{\partial c} \frac{\partial g}{\partial \sigma^{\prime}} \frac{\partial c}{\partial \varepsilon_{v}^{p}}
\end{aligned}
$$

\footnotetext{
* Corresponding author: saeed.tourchi@gmail.com
} 


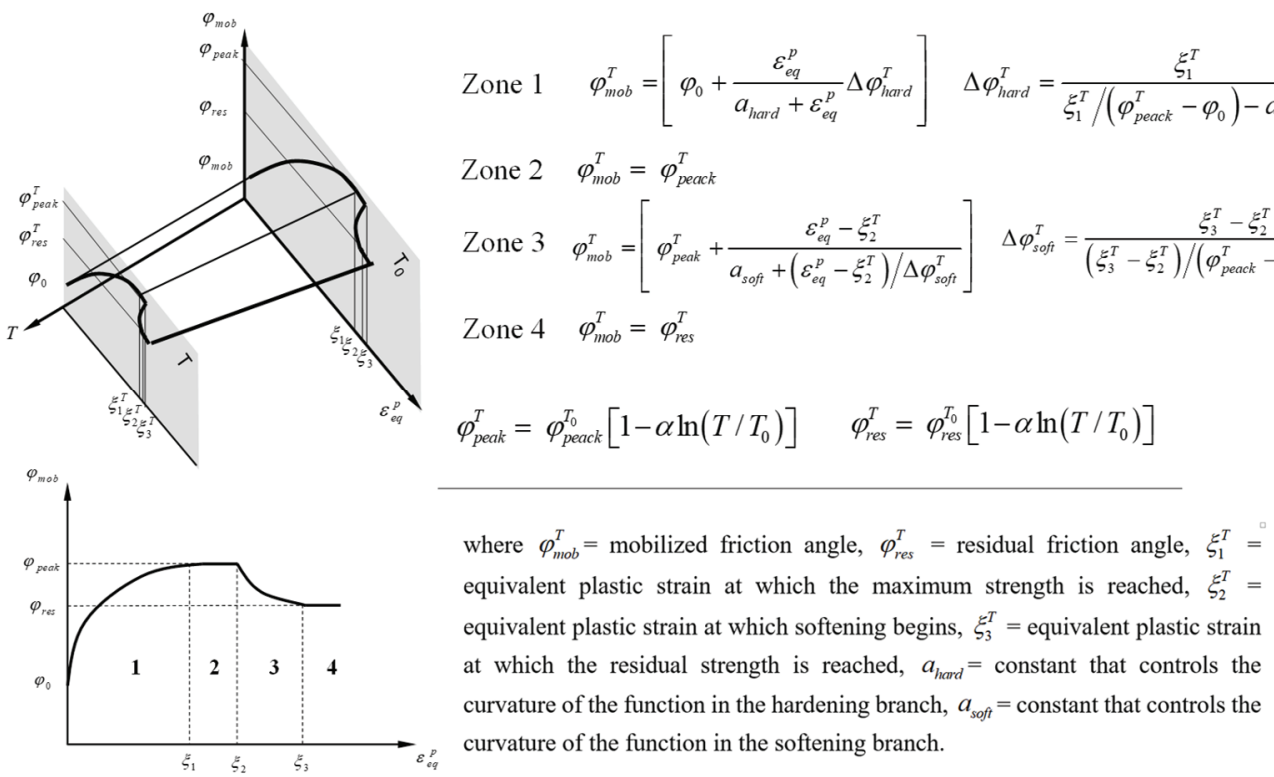

Fig 1: Evolution of friction angle with temperature in the hardening and the softening regimes (Tourchi 2020)

To illustrate the applicability of the model, a finiteelement simulation of the coupled THM behaviour of the ALC1604 in situ heating test has been performed (Tourchi et al. 2020; Bumbieler et al. 2021). The effect of a temperature increase on the excavation damaged zone (EDZ) is shown in Fig. 2. The thermoplastic-induced extension of the EDZ during heating is shown in Fig.la. The thermoplastic evolution of the EDZ can also be observed in the contours of the plastic multiplier (Fig 2a).

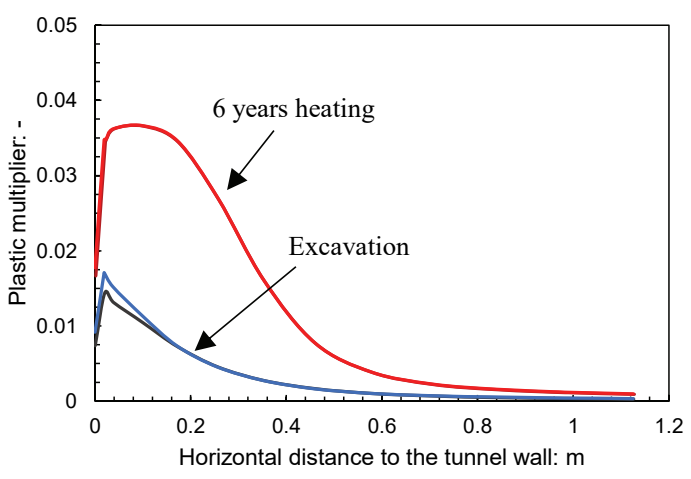

(a)

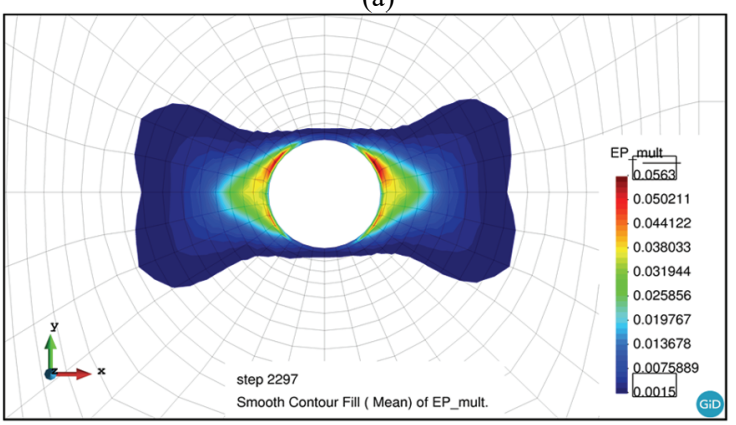

(b)

Fig. 1: (a) computed plastic multiplier after excavation and at the end of heating (2422 days); (b) obtained configuration of the EDZ in terms of the plastic multiplier at the end of the heating phase.

\section{References}

1. Bumbieler F, Plúa C, Tourchi S, et al. (2021) Feasibility of constructing a full-scale radioactive high-level waste disposal cell and characterization of its thermo-hydro-mechanical behavior. Int J Rock Mech Min Sci 137:104555.

2. Mánica M, Gens A, Vaunat J, Ruiz DF (2017) A time-dependent anisotropic model for argillaceous rocks. Application to an underground excavation in Callovo-Oxfordian claystone. Comput Geotech 85:341-350.

3. Tourchi S (2020) THM analysis of argillaceous rocks with application to nuclear waste underground storage. BarcelonaTech (UPC)

4. Tourchi S, Vaunat J, Gens A (2020) A full-scale in situ heating test in Callovo-Oxfordian claystone: observations, analysis and interpretation. Comput Geotech 133:1-54. 